\title{
LA HISTORIOGRAFÍA CONSTITUCIONAL EN LA FORMACIÓN NACIONAL DE CHILE: 1810-1833. ENFOQUES Y DISCUSIONES
}

\author{
THE CONSTITUTIONAL HISTORIOGRAPHY IN THE CHILEAN \\ NATIONAL FORMATION: 1810-1833. APPROACHES AND DEBATES
}

Javier Francisco Jesús Infante Martin*

El tema propuesto abarca dos disciplinas que vienen a confluir en un punto en común: ambas analizan, desde ópticas distintas, una misma época y un mismo problema. Nos referimos por un lado al análisis histórico propiamente tal, que estudia los hechos desde una perspectiva general, tomando en cuenta obviamente los distintos subenfoques que pueden existir, y la historia constitucional, que analiza el proceso jurídico a que dio lugar la independencia, o que se inició con ella. Por lo mismo, analizaremos el fenómeno desde esas dos perspectivas. No se crea que pretendemos realizar un análisis independiente de cada una de ellas, sino simplemente ver primero cuáles son las características propias de cada una, para luego entrar a estudiar sus elementos comunes. En Chile, gran parte de la literatura historiográfica ha seguido la perspectiva institucional o constitucional como hilo central de su discurso ${ }^{1}$. Ello puede ser visto como un defecto, toda vez que

\footnotetext{
* Doctor en Derecho, Universidad de Navarra. DEA en Historia del Derecho y Máster oficial en Derecho, Universidad de Navarra. Master in Business Law, Universidad Adolfo Ibáñez. Profesor de Historia del Derecho, Pontificia Universidad Católica de Chile. Correo electrónico: jfinfante@uc.cl

1 "Nadie puede dudar que entre los principales defectos de nuestra historiografía se encuentra el predominio casi absoluto del enfoque jurídico y politico institucional'. Jocelyn-Holt (1985), p. 213.
}

deja de lado otras perspectivas igualmente interesantes, sin embargo poco aplicables al tema que nosotros pretendemos estudiar. Si bien es posible, por ejemplo, hacer un análisis de aquella época centrándose en otros factores, creemos que la historiografía institucional es bastante acertada para acercarse al período de la formación nacional, ya que gran parte de su historia necesariamente se ve forjada por sus proyectos políticos.

A grandes rasgos, podemos reconocer grupos bastante consolidados en la historiografía de la Independencia. Estos muchas veces coexisten y comparten características unos con otros.

En primer lugar, y no siendo necesariamente uniforme en sus contenidos, podemos citar a la primera escuela de historiadores chilenos ${ }^{2}$, ubicándolos en la segunda mitad del siglo XIX. Esta escuela, influida en gran medida por Andrés Bello, siguió un estilo historiográfico narrativo, "estrechamente ceñido a los hechos, destacando su individualidad", de este modo, crear una base que cimentara el camino a los futuros historiadores, dado

\footnotetext{
2 Collier se refiere a los mejores exponentes de este período como "los grandes historiadores narrativos -Diego Barros Arana, Miguel Luis Amunátegui, Benjamín Vicuña Mackenna...”. Collier, Simon (2012), pp. 27-28.

3 Gazmuri, Cristián (2006), Tomo I, p. 77.
} 
el nivel de desarrollo en que se encontraba la historia de Chile ${ }^{4}$. Para Bello, la historia debía tener una base clara, en que los hechos se encontrasen debidamente narrados y compilados. En este sentido, el mismo Bello reconoce su preferencia por el método narrativo (ad narrandum) versus el método filosófico (ad probandum), al señalar que "cada uno de los métodos tiene su lugar; cada uno es bueno a su tiempo...", no obstante "...cuando la historia de un país no existe, sino en documentos incompletos, esparcidos, en tradiciones vagas, que es preciso compulsar y juzgar, el método narrativo es obligado..." . Finalmente el método de Bello terminó por imponerse. De acuerdo a sus postulados se escriben las obras de los historiadores chilenos del siglo XIX. Su estilo extenso y repetitivo, así como la inclusión de amplias citas documentales, es el sello característico del triunfo del método elegido ${ }^{6}$. La marca de Bello perduró hasta fines del siglo XIX. Como señala Guillermo Feliú, “...Los historiadores no hicieron de la historia obra de arte, porque Bello no quiso que se hiciera, ni permitió tampoco que se filosofase en su nombre".

Se suele denominar a esta corriente como historiografía patrio-nacional, también conocida como historia patria o bien historia nacional o liberal ${ }^{8}$. Sus máximos exponentes, Barros Arana, Vicuña Mackenna o los hermanos Amunátegui, fueron discípulos de Bello9 . Esta escuela se caracteriza

\footnotetext{
4 Bello, Andrés, en El Araucano, 28 de enero de 1848 .

5 Ídem.

6 Gazmuri, Cristián (2006), p. 76.

7 Feliú, Guillermo (1934), p. 8.

8 Quintero, Gilberto (2007), p. 102.

9 “...Historiador sobre todo, bibliógrafo, erudito, $\mathrm{Ba}$ rros Arana llevó a la perfección la doctrina historiográfca levantada por Bello, en contraposición a la sostenida
}

por una visión tradicional de la historia, que viene a tener como nota central la influencia liberal/conservadora en la política americana de entonces. En exponentes de ambas corrientes se aprecia con claridad una tendencia hacia la exaltación de lo nacional $^{10}$.

El binomio patriotas-realistas jugó entonces el rol principal, transportándose más allá de la época de las guerras de la Independencia hasta la etapa republicana, consolidándose en la lucha entre conservadores y liberales, más tarde llamados pelucones y pipiolos respectivamente. La existencia de dos fuerzas sociales que chocaron inevitablemente en la primera década del siglo antes pasado, y que trajo aparejado el desmembramiento del Imperio español será una hipótesis frecuente -sino constante- en la narración de la historia por parte de la escuela que analizamos. Era el liberalismo que venía a dejar sus primeras huellas en suelo americano. En este sentido, la escuela del siglo XIX veía en la revolución un proceso que vino a demoler las antiguas bases coloniales y a sembrar el campo para una sociedad nueva ${ }^{11}$. Esta escuela se caracteriza por

por Lastarria. Impuso a su obra el sello profundo de su genio en la aplicación del método analítico en la historia...”. Feliú, Guillermo (1934), p. 9. El autor menciona a Lastarria, quien se inclinaba por el método filosófico, y cuya obra se consagraba a la condena del pasado colonial y la exaltación de las virtudes del presente republicano. GAZMURI, Cristián (2006), p. 76.

10 Gazmuri, Cristián (2006), p. 85.

11 "La revolución de la Independencia ha operado en la América Española la más radical de las transformaciones. Medio siglo ha bastado para sustituir a la antigua sociedad, que parecía reposar sobre cimientos de granito, otra esencialmente distinta por las ideas, por las costumbres, por la ilustración, por la industria, por las instituciones. Los actuales hispano-americanos necesitan hacer esfuerzos de imaginación para poder figurarse lo que eran sus abuelos, tal vez lo que eran sus padres.", Amunátegui, Miguel Luis (1870), Vol. I, pp. v-vi. 
tratar de legitimar las guerras de Independencia americanas, justificando las luchas habidas entre las élites criollas americanas y los peninsulares en América, así como por tratar de explicar las razones de por qué dichas élites tomaron el control de los nuevos estados soberanos que resultaron de dicho proceso. Como señala Gazmuri, ello se explica por la pertenencia de los mismos historiadores a la clase aristocrática nacional y santiaguina ${ }^{12}$.

Esta primera generación de historiadores y su obra, ha sido criticada por diversas razones ${ }^{13}$.

Las pasiones que aún despertaba la guerra de Independencia, vivas aun cuando esta escuela estaba en su apogeo, distorsionó la visión que estos historiadores plasmaron en sus obras. La cercanía con los hechos objeto del estudio la encegueció ante la realidad. Su tratamiento muchas veces abiertamente parcial a favor de la causa de la Independencia, manifestado tanto en la aceptación de los argumentos que sustentaban aquella postura y la consecuente omisión o preterición de los argumentos en contra -sin siquiera mencionar el tratamiento que se daba a los principales personajes de uno u otro partido- son sin duda

\footnotetext{
12 Gazmuri, Cristián (2006), p. 85.

13 Por ejemplo para Gabriel Salazar, el trabajo de Barros Arana se encuentra en un pedestal que inhibe a los historiadores de realizar críticas a su obra: "su credibilidad es mayor que la consistencia teórica de su hermenéutica... Pero es evidente que, más allá de su erudición documentada y su innegable meticulosidad descriptiva, sus afirmaciones "caracterizadoras" de una persona o situación -que son muchas, tantas como sus proposiciones empiricas - tienden a ser reiterativas $y$, a menudo, de gran simplismo, sobre todo porque, una con otra, engarzan tesis politicas subliminales que desnudan su afiliación oligárquica, mercantil y pelucona, que se trasluce notoriamente en su interpretación del periodo 1823-1837”. Salazar, Gabriel (2005), p. 29.
}

un defecto que resta valor a los trabajos de la época ${ }^{14}$.

En el caso chileno, ello se vio aumentado por la necesidad de renegar del pasado español, debido no solo al recuerdo de la Independencia, sino a la guerra contra España del año 1864, que culminó con el bombardeo del puerto de Valparaíso -incluyendo la destrucción de gran parte del comercio establecido por numerosos comerciantes europeos- por parte del almirante Casto Méndez Núñez. Ello no ayudó, en el caso chileno, sino a ahondar aún más el odio hacia lo español, odio que se reflejó de dos maneras: por un lado -como ya hemos mencionado-, mediante una visión parcial la guerra de Independencia, y por otro, mediante tendencias laicistas, entendiendo esto como una manera de renegar de los valores tradicionales heredados de España ${ }^{15}$.

Una nueva generación de historiadores surge de la escuela patrio-nacional: nos referimos a historiadores de la talla de José Toribio Medina Castro, Guillermo Feliú, Ramón Sotomayor Valdés o Domingo Amunátegui Solar. Estos se caracterizaron -especialmente los dos primeros- por publicar compilaciones de documentos relativos a la época de la Independencia y formación de la República, muchas de las cuales sirven de fuentes hasta nuestros días. Al mismo tiempo realizaron un estudio más acucioso y acabado sobre el pasado colonial,

\footnotetext{
14 Quintero califica al producto de esta escuela como "partidario, militante, intolerante y con una profunda preocupación por echar las bases del nuevo edificio sociopolítico en el sentido de pretender mostrar la contienda independentista como una guerra de liberación nacional y nunca como una guerra civil; como una obra de la élite ilustrada y filantrópica, pero mal comprendida por los sectores populares, y no como una revolución sociopolítica”. QuinTero, Gilberto (2007), p. 102. 15 Vial, Gonzalo (1965), p. 256; Gazmuri, Cristián (2006), p. 85.
} 
sin encontrarse tan influidos por este como para perder la objetividad en sus conclusiones. Una obra digna de ser nombrada es la denominada Colección de Historiadores y de Documentos Relativos a la Independencia de Chile, serie de publicaciones en la cual se publican, por ejemplo, las Actas del Cabildo de Santiago durante la Independencia.

Mención aparte merece el historiador Luis Galdames, quien dedicó un trabajo exclusivamente al tema de la historia constitucional. Su obra destaca por el profundo análisis realizado del contexto histórico en el cual las obras constitucionales presentadas fueron redactadas, así como los certeros juicios entregados por el autor respecto a las falencias que aquejaban a cada uno de ellos, no obstante fue contemporáneo a los mismos.

Luego de esta escuela de pensamiento histórico, se nos presenta otro estilo historiográfico bastante distinto a su escuela predecesora, aunque podemos considerarla en cierta medida un subproducto de aquella. Esta escuela es de corte ideológico, basado en el positivismo y en el materialismo histórico ${ }^{16}$. Esta corriente en aquella época se vio influida también por la ideologización de los autores (corriente que luego volvería a presentarse años más tarde). Así tenemos a intelectuales -no necesariamente historiadores- como Luis Emilio Recabarren $^{17}$, quien en su discurso - posteriormente publicado- "Ricos y Pobres", en 1910, pretende justificar la efervescencia política de aquellos años -nacimiento del socialismo en Chile- mediante una justificación histórica. Recabarren pretendía demostrar que el pueblo - proletariado- se encontraba en una

\footnotetext{
16 Quintero, Gilberto (2007), p.103.

17 Socialista, fundador del Partido Comunista en Chile.
}

situación desfavorable desde los inicios de la vida política nacional, en incluso desde la Colonia. Creemos que este anacronismo, no obstante el interés que puede presentar como objeto de estudio per se, no tiene ni merece una mayor presencia en este trabajo $^{18}$. Es cierto, como anticipábamos, que Recabarren fue un intelectual y no necesariamente un historiador, más fue el primero en dar curso a una historiografía abiertamente ideológica. Sus aguas han sido seguidas por historiadores -no necesariamente historiadores/juristas- que han tratado el tema desde una óptica marxista, como Luis Vitale $^{19}$ o Hernán Ramírez Necochea ${ }^{20}$.

También desde 1940 en adelante, aparecen exponentes de otras posturas,

${ }_{18}$ En su discurso, Recabarren señalaba que "trazar con expresiones sinceras los pensamientos que en mi se albergan sobre el siglo transcurrido bajo el régimen de la República, y procuraré que estas expresiones sean el retrato de la verdad, es decir, de la verdad como yo la comprendo, como yo la siento, ya que desgraciadamente existen diferencias para apreciar la verdad... (para luego advertirnos que en la Colonia) Se vivía en este pais bajo el régimen de la sociedad feudal, algo atenuada si se quiere, pero con todas las formas de la esclavitud y con todos los prejuicios propios del feudalismo. El sometimiento demasiado servil de la clase esclava entregada en su mayor número a la vida pastoril y a la agricultura era tina circunstancia que no provocaba ninguna acción de la clase señorial, en que pudiera notarse como hoy, sus crueldades". RecabarRen, Luis Emilio (1910), pp. 1-2. Es decir, mediante el discurso de la lucha de clases, se pretende crear un eje que tenga a dicho conflicto como forjador de la historia. No obstante, como ya dijimos, Recabarren no era un historiador, y su visión del marxismo no era rigurosa ni profunda.

19 Vitale, Luis (1967): Interpretación marxista de la Historia de Chile.

20 Por ejemplo Ramírez, Hernán (1959): Antecedentes económicos de la Independencia de Chile. Javier González señaló sobre esta obra: "La nueva obra del señor Ramírez, inspirada en un punto de vista unilateral, no sirve, pues, para comprobar la verdad de la teoría materialista de la historia, ni significa tampoco un gran aporte en el campo de la historia de Chile...", GonZÁlez, Javier, (1968), pp. 373-375. 
como Jaime Eyzaguirre y Francisco Antonio Encina, y por qué no mencionar a Alberto Edwards Vives, pese a su escaso aporte al estudio de la época en cuestión y a no ser contemporáneo a los demás autores mencionados, no obstante su parentesco intelectual.

Estos autores fueron claros expositores del movimiento antirracionalista, tendencia que nace en respuesta al positivismo y racionalismo del siglo anterior, y que bajo la influencia alemana de autores como Spengler, Kant y Hegel $^{21}$, sostenían que el camino racional y científico no era la única vía para acceder a la verdad y el conocimiento. También recibieron la herencia de los grandes historiadores del siglo XIX, y a raíz de la inestabilidad política de la primera mitad del siglo XX en Chile, con el surgimiento de caudillos populistas como Alessandri e Ibáñez del Campo, tuvieron como misión rescatar el mensaje portaliano, entendiendo este como la exaltación de la figura impersonal y autoritaria, única capaz de brindar orden en un país acostumbrado culturalmente a este tipo de gobierno: el presidencialismo.

Jaime Eyzaguirre, por otro lado, tenía una visión hispanista ${ }^{22}$ y católica del proceso de Independencia, lo que hizo que este omitiese o bien restase importancia a hechos relevantes en la Independencia nacional. En su obra Ideario y Ruta de la Emancipación de Chile, señaló por ejemplo, que la alegada preterición de los criollos de los cargos públicos no puede alegarse como causa suficiente de la Independencia, y citó ejemplos de criollos que efectivamente ocupaban cargos de importancia en la

${ }^{21}$ Gazmuri, Cristián (2005), p. 195.

22 Gazmuri, Cristián (2005), p. 198; 2009, pp. 82 83. administración colonial. También sostuvo que "La imagen de un gobierno arbitrario y despótico, fraguada como lógico corolario de la revolución de la independencia, no encuentra en estos antecedentes ningún asidero....". Finalmente señaló que "De acuerdo con el concepto estatal dominante, la participación politica restada al pueblo, le era devuelta en beneficios de orden espiritual y material: ensanche de la instrucción, fundación de nuevas ciudades, fomento de las obras públicas. El lema del "despotismo ilustrado": "todo para el pueblo, sin el pueblo", encontraba asi su plena aplicación" 23 .

Si bien es cierto que la exclusión de criollos de cargos de importancia fue realmente menor a lo que se normalmente se cree, lo importante de destacar es que ello sí existió como política estatal, creándose muchas veces conflictos por su aplicación. Del mismo modo, señalar que los gobernantes eran ejemplos de "laboriosidad y espíritu de progreso" es caer en generalidades, ya que si bien estos y sus respectivos gobiernos fueron efectivamente respetables y procuraron el bien común, no por ello perdían su carácter autoritario, viéndose ello claramente en algunos casos, como el tristemente conocido caso del Gobernador García Carrasco.

En esta misma línea cabe citar a Alberto Edwards Vives quien en sus obra " $L a$ fronda Aristocrática" y "La Organización Política de Chile" -además de un opúsculo titulado La Constitución de 1833- se presenta como un defensor del régimen autoritario que comienza con el ministro Diego Portales en la tercera década del siglo XIX, justificando el autoritarismo de los gobiernos conservadores -especialmente en relación con el gobierno del Presidente Montt (1841-1851)- bajo la premisa de

${ }^{23}$ EyzaguirRe, Jaime (1957), p. 52. 
que Chile se encontraba acostumbrado a la tradición monárquica, y que solo un presidencialismo reforzado podía lograr ordenar al país y llevarlo a las virtudes republicanas o parlamentarias. Para Mario Góngora, este análisis que Edwards hace de la historia del siglo XIX en Chile, es la "mejor y mayor interpretación de la historia del siglo pasado" 24 . De este modo, Chile carecía de la virtud republicana, por lo que el autoritarismo vendría a reemplazar la obediencia al Rey por la obediencia a la autoridad democráticamente electa en la República. Una definición del Estado portaliano -en palabras de Edwards- la encontramos en una carta escrita por el propio Portales en marzo de $1822^{25}$.

Esto era, para Edwards, el concepto del "Estado en forma", expresión que el autor reconoce tomar de Spengler ${ }^{26}$. Este "Estado" sería el producto de la renuncia por parte de la "fronda aristocrática" a sus pretensiones de poder, y el abandono que de él hacen en personajes fuertes y autoritarios -hecho que explica que tres de los cuatro decenios presidenciales del siglo XIX chile-

\footnotetext{
24 Góngora, Mario (1986), p. 74.

25 “...La Democracia, que tanto pregonan los ilusos, es un absurdo en los paises como los americanos, llenos de vicios y donde los ciudadanos carecen de toda virtud, como es necesario para establecer una verdadera República. La Monarquía no es tampoco el ideal americano: salimos de una terrible para volver a otra y iqué ganamos? La República es el sistema que hay que adoptar; ¿pero sabe cómo yo la entiendo para estos países? Un Gobierno fuerte, centralizador, cuyos hombres sean verdaderos modelos de virtud y patriotismo, y asi enderezar a los ciudadanos por el camino del orden $y$ de las virtudes. Cuando se hayan moralizado, venga el Gobierno completamente liberal, libre y lleno de ideales, donde tengan parte todos los ciudadanos. Esto es lo que yo pienso y todo hombre de mediano criterio pensará igual...". Epistolario de Diego Portales, Tomo I (Edición 2004), pp. 8-9.

26 Edwards, Alberto (1928, Ed. 2005), p. 56.
}

no, hayan sido conservadores y autoritarios (Prieto 1831-1841; Bulnes 1841-1851 y Montt 1851-1861).

También forma en esta escuela Francisco Antonio Encina, quien en su obra "La Literatura Histórica Chilena y el Concepto Actual de la Historia", realiza una crítica y distingue entre una primera fase en la elaboración histórica, que consiste en la investigación y recopilación de fuentes e información, y otra constituida por la historia propiamente tal, que consiste en la interpretación y análisis que el historiador realiza con base en el trabajo del investigador. Su crítica se centra en que de los grandes historiadores del siglo XIX -citando a Barros Arana de manera expresa- dejaron a la Historia "flotando entre la investigación y la historia" 27 , al confundir ambas disciplinas. Un detalle importante en Encina -y difícil de pasar por alto- es su simpatía intelectual hacia la obra de Nicolás Palacios, "Raza Chilena" (1918), obra cargada de ideas nacionalistas, más una oda al carácter chileno que otra cosa, y a quien se ha catalogado como un pensador de corte racista. No trepida en señalar que Palacios es quizás la única excepción dentro de los historiadores chilenos, pues posee la agudeza psicológica necesaria para visualizar la verdad en un ambiente lleno de prejuicios que han "aplastado el cerebro de nuestros historiadores", llevando a cometer errores científicos y psicológicos ${ }^{28}$. Asimismo, Encina también fue duramente criticado por su método, que en algunos casos consistió en tomar literalmente el trabajo de otros historiadores como propio $^{29}$.

\footnotetext{
27 Encina, Francisco (1935), p. 39.

28 EnCinA, Francisco (1935), p. 47.

29 Sobre este punto, véase el interesante trabajo de Donoso, Ricardo (1969 y 1970): Francisco A. Encina Simulador.
} 
Lo criticable en estas corrientes historiográficas radica en la falta de aquella prolijidad necesaria para realizar un análisis claro de la época que se estudia, especialmente a la hora de emprender el análisis de fuentes. En este sentido, así como la escuela anterior se vio altamente ideologizada por el liberalismo como fuerza que ayudó a lograr la independencia de la dominación española, y elaboró una idea basada en la rivalidad entre ambas regiones del Imperio y el despotismo de España hacia América, esta escuela tampoco logró mayores avances en la obtención de una visión imparcial y crítica de la Independencia. Si bien hubo intentos y efectivamente se logró un avance con relación a la escuela anterior, autores como los nombrados ponen de manifiesto que aún nos encontramos ante un campo complejo, en el cual es difícil llegar a buen puerto. Pero no solo el hecho de analizar los sucesos de la independencia desde la óptica ideológica es criticable en estos autores. También marcó el trabajo de estos historiadores el hecho de que estos basaron y fundamentaron su trabajo en gran medida en aquello que ya se había dicho por los autores de la escuela anterior, por lo que muchos de los vicios de aquellos pasaron a estos.

Con posterioridad tuvo lugar el nacimiento de aquella escuela de historiadores que realizaron su estudio desde una perspectiva estructural, ya globalmente o bien desde perspectivas locales, herederos chilenos de la escuela de los Annales o de la Nouvelle Histoire. Para esta escuela el proceso de independencia se considera como una parte de un todo más grande, es decir, ya no se estudia únicamente la Independencia de Chile como un todo excluyente de lo que pasaba en el resto del mundo y con fundamento en sus propias circunstancias, sino que el proceso va necesariamente de la mano de procesos aún mayores que tuvieron dentro de sus consecuencias la Independencia Nacional. Es decir, se comienzan a fijar en las reglas comunes que vinieron a provocar que el proceso independentista afectara a cada uno de los territorios que componían la América española ${ }^{30}$. Para esta corriente, no solo es importante la ubicación del fenómeno dentro de un proceso mayor, sino también el estudio de las características internas de cada caso. Así, en el caso chileno se comienza a estudiar el fenómeno de la independencia tanto desde una óptica americanista como desde el punto de vista de las causas locales. En este sentido, cabe citar a los profesores Mario Góngora, Rolando Mellafe, Julio Heise y Sergio Villalobos.

El mérito de los trabajos de Sergio Villalobos, en sus obras Tradición y reforma en 1810 (1961), o El comercio y la crisis colonial (1968), o bien las investigaciones realizadas por Mario Góngora, radica en que "al analizar la continuidad que se extiende desde la segunda mitad del siglo XVIII hasta la década del 30 del siglo XIX, permitieron aclarar aspectos fundamentales del proceso de la Independencia que hasta entonces habian quedado sin explicación. Gracias a estas investigaciones comprendemos mejor por qué la ruptura política con España no se tradujo en una ruptura general de las estructuras existentes, por qué la sociedad bajo el régimen republicano se siguió comprendiendo como sociedad cristiana, por qué se mantuvo la religión católica como religión oficial de la República $y$ por qué el gobierno republicano se sintio plenamente legitimado para ejercer su tutela

\footnotetext{
${ }^{30}$ Quintero, Gilberto (2007), p. 104; ViaL, Gonzalo 1965, p. 258.
} 
sobre la Iglesia e intervenir en el régimen interno de ésta..." 31.

Resalta su obra Tradición y Reforma en 1810, que relata y demuestra de manera ejemplar el ritmo político y social que durante la colonia se marcó en Chile y que se mantuvo ininterrumpido hasta 1810 con el establecimiento de la Primera Junta Nacional de Gobierno. En este sentido es destacable cómo Sergio Villalobos viene a romper, por una parte, con mitos históricos. Un ejemplo de ello es la Guerra de Arauco, la cual de acuerdo a su postura no fue tan cruenta como otros historiadores nos dan a saber ${ }^{32}$, y por la otra viene a establecer que hasta 1810 no existió en Chile una animadversión tan declarada hacia la dominación española, sino que fueron casos aislados y siempre dentro de un marco de fidelidad incuestionable al monarca. En este sentido, y contrariamente a lo señalado por Vial ${ }^{33}$, Villalobos nos parece uno de los mejores exponentes de esta nueva corriente,

31 Krebs, Ricardo (1985), p. 8.

32 Por ejemplo, Jaime Eyzaguirre se refiere a Chile como el "Flandes Indiano", recordando las palabras del padre Diego de Rosales, quien "...quiso hacer pasar a Chile al marco de la historia como la piedra de detención de la mas grande potencia del mundo y llamó a esta tierra Flandes Indiano, nombre que habla mucho de hazañas pero también de grandes desalientos para la caballería.", Eyzaguirre, Jaime (1948), p. 41; Mario Góngora, en su famoso "Ensayo...", habla del país como Chile, tierra de guerra, diciendo que "La imagen fundamental y primera que de Chile se tiene es que constituye, dentro del Imperio Español de las Indias, una frontera de guerra, "una tierra de guerra".", GÓNGORA, Mario (1986), p. 63.

33 Cfr. Vial, Gonzalo (1965), p. 258. "Por último, no ha faltado moderno defensor a la tesis tradicional, en la persona de Sergio Villalobos", opinión que nos parece errada, toda vez que el mismo Villalobos señala en su obra que el problema de la Independencia "ofrece mayor interés por plantear la cuestión de los origenes de un fenómeno y tener que basarse obligadamente en un balance del período colonial', Villalobos, 1961 (Ed. 2006), p. 17. toda vez que enfrenta el problema abordando directamente las fuentes y reconociendo que la Independencia hunde sus raíces en el período colonial, el cual hace las veces de incubadora al patriotismo que se viene a manifestar en 1810 y los posteriores intentos de autogobierno.

Asimismo dicha obra nos presenta el Chile colonial desde las perspectivas del día a día de quienes vivieron aquellos años mediante la narración sucinta de breves episodios posteriormente contextualizados en un análisis macro. Un ejemplo de ello se presenta con la captura de Fernando VII y el efecto que dicho evento tuvo en los súbditos americanos, cómo estos reaccionaron con espanto y decisión ante las noticias de las invasiones napoleónicas y el cautiverio de su Rey, así como las molestias que previo a lo anterior habían causado la aplicación de las reformas de finales del siglo XVIII, relativas al alza de impuestos, o a la derogación de ciertos beneficios económicos que estaban en manos de privados, para volverlas competencias públicas - por ejemplo el cobro de la alcabala o los estancos de tabaco-. Por ello creemos que el trabajo en cuestión no pertenecería al segundo grupo de historiadores nacionales -ya se trate de los grandes compiladores, o bien aquellos que trataban de integrar la historia en movimientos contemporáneos- sino que se trata de un trabajo que presenta un análisis crítico a la obra previa presentando conclusiones novedosas e interesantes y rompiendo con muchos de los paradigmas que hasta entonces se venían repitiendo una y otra vez por sus antecesores. Del mismo modo su posterior obra, El Comercio y la Crisis Colonial (1968), viene a romper con el paradigma histórico -vigente incluso hasta nuestros días- relativo a la dependencia exclusiva por parte de las colonias del comercio con la 
península, y sostiene que dicha premisa es absolutamente falsa. Por el contrario, en sus páginas se expone con claridad y de manera muy bien documentada, la realidad económica y comercial que se vivió en la colonia, especialmente en los años que vinieron a preceder inmediatamente al movimiento de independencia. Es por ello que tajantemente señala que "debemos rechazar, en consecuencia, al libre comercio como antecedente de la Independencia. Si algún descontento bubo respecto al comercio, fue debido más bien a su gran desarrollo. Los antecedentes económicos de la Emancipación deben buscarse en otros aspectos más significativos, que levantaban la protesta de los criollos o les hacian soñar con un futuro de gran prosperidad"34. Ello se debía fundamentalmente a que las fronteras no estaban tan cerradas al comercio extranjero como se ha señalado tradicionalmente, y factores como el contrabando, así como la concesión de permisos reales para operar en el mercado del Pacífico a naves extranjeras o españolas, vinieron a establecer un libre mercado de facto, que provocó incluso un desincentivo a la industria local ${ }^{35}$. Dicho texto debe ser necesariamente complementado con la obra de Álvaro Jara, El Imperio Español en América, una Historia Económica. En esta importante y trascendental obra, queda manifiesta de manera clarísima la política económica general que tuvo la Metrópoli en las Indias, así como las inconsistencias y la fragilidad de las mismas, tesis que corrobora, en parte, la postura de Villalobos.

Pese a lo novedoso de su trabajo, estas obras aún no encajan dentro de la tendencia actual de analizar el proceso de Independencia, que lo hace desde una óptica global, teniendo en cuenta el pensamiento y las ideas $-y$ muchas veces las maneras de comunicar dichas ideas- de los actores de la época.

Un trabajo fundamental sobre la formación política de Chile, pese al escaso análisis de la época que nos interesa en el presente estudio, es el Ensayo Histórico sobre la noción de Estado en Chile en los Siglos $X I X$ y XX, de Mario Góngora. Esta obra podría considerarse alineada con un trabajo ya mencionado: La Fronda Aristocrática de Edwards. En ambas queda manifiesto un concepto de Estado nacional -idea a la que también podría adherir la obra de Jaime Eyzaguirre en cuanto se considerase su hispanismo nacionalista- formado a partir del orden político. Independiente del orden de los factores -el Estado o la Nación-, lo que intentan destacar ambos autores es el surgimiento de la nación a partir del orden político: el concepto spengleriano del Estado en forma, situación que se diluiría con el pasar de los años y la superación del espíritu de fronda ${ }^{36}$.

Mención aparte merece la obra de Simon Collier, quien aportó al período con un trabajo derivado de su tesis doctoral, en la cual se estudia el pensamiento político de aquellos patriotas a quienes tocó llevar a cabo la tarea de la Independencia. Es por lo mismo, un trabajo sobre historia de la ideas, sin abarcar el proceso completo o constituir un estudio pormenorizado de aquel episodio. Pese a lo anterior constituye una de las obras más trascendentales sobre la Independencia en el pasado siglo. Su obra más importante del período en cuestión, Ideas y política de la Independencia

\footnotetext{
36 Góngora, Álvaro (1990), p. 40.
}

34 Villalobos, 1967 (Ed. 2006), p. 262.

35 Ob. Cit., p. 10. 
Ensayos y Crónicas

Chilena 1808-1833 37 , explica con claridad las bases intelectuales de los primeros patriotas que participaron en la Independencia, así como la influencia europea e ilustrada que en ellos se reflejaba, a través de sus discursos o publicaciones. También expone las condiciones sociales y políticas que favorecieron un ambiente propicio a la causa autonomista, posteriormente independentista. Analiza también los primeros intentos de gobierno que hubo en el país, y la forma que se intentó dar a dichas administraciones, conciliando de manera clara la historia institucional con la historia política y social, así como la influencia de partidos, familias o intereses políticos diversos. Dicho trabajo fue complementado con un segundo libro titulado Chile: la construcción de una República. 1830-1865, politica e ideas, que enfrenta con igual éxito el estudio del período inmediatamente posterior.

Julio Heise por su parte, aborda en 150 años de evolución institucional, un análisis más jurídico o centrado en la perspectiva institucional, centrado tanto en la historia de las ideas que fundamentaban los cambios y proyectos políticos -línea que retomará años más tarde en su siguiente obra Años de formación y aprendizaje politicos 1810-1833- así como en los proyectos políticos propiamente tales que se llevaron a cabo en aquellos años. Heise presenta la Independencia chilena como un reflejo de los principios que se estaban esgrimiendo por los revolucionarios liberales españoles, y que se sostenía en tres principios básicos: "1) el derecho a la independencia, esto es, el deber de lucha contra la dominación extranjera; 2) el enérgico repudio del absolutismo y el ejercicio activo de la soberanía: esta radica

\footnotetext{
37 La primera edición en inglés es de 1967, y en español de 1977. Fue reeditado el año 2012.
}

en el pueblo y consiste en la facultad de darse libremente el gobierno que se juzgue mejor, y 3) como una consecuencia de lo anterior, se reconoce el poder constituyente de la nación: la constitución es indispensable para subordinar el poder al derecho"38. Por lo anterior, para Heise el período de la Independencia es el momento en que nuestro país ensaya las ideas políticas conocidas y las trata de adaptar a la realidad concreta, mediante la serie de ensayos constitucionales vigentes en los primeros años de vida independiente ${ }^{39}$.

Actualmente, la historiografía se ha identificado con el análisis político de la época republicana, y la búsqueda de ideas democráticas en aquellos primeros años, con la finalidad de derribar el mito de la supuesta excepcionalidad del régimen institucional chileno heredado de Portales.

Uno de los exponentes de esta tendencia es Alfredo Jocelyn-Holt ${ }^{40}$. En su obra, el autor deja ver cómo la Independencia de Chile no es un episodio aislado, provocado únicamente por la coyuntura del momento, sino que se trata de un proceso de larga data, arrastrando sus raíces desde mediados del siglo XVIII -y que aún no habría detenido- consistente en la transformación de una sociedad tradicional, como lo era la sociedad chilena colonial, en una sociedad moderna ${ }^{41}$. Este lente bajo el cual Jo-

\footnotetext{
38 Heise, Julio (1976), pp. 16-17; (1978), p. 29.

39 HeIse, Julio (1976), p. 21.

40 Principalmente en su obra "La Independencia de Chile. Tradición, modernización y mito", aunque también en trabajos menores relativos al pensamiento republicano una vez consolidada la Independencia. No obstante, el autor pese a ser contemporáneo, no puede ser catalogado como un autor perteneciente a la escuela de la Nueva Historia, toda vez que tiene un enfoque excesivamente político -tanto de las ideas como de sus pensadores-, aunque sin caer en la historiografía social, como es el caso de Gabriel Salazar.

${ }^{41}$ Jocelyn-Holt, Alfredo (1992), p. 113.
} 
celyn-Holt viene a analizar el período de la Independencia, provoca precisamente que su visión de la historia no se identifique con la tendencia actual del trabajo histórico, que viene a tratar de sistematizar las diferentes estructuras existentes y de analizar el ideario que se encontraba en sus principales agentes, idea que es también planteada por Francois-Xavier Guerra, en su trabajo $\mathrm{Mo}$ dernidad e Independencias, Ensayos sobre las revoluciones hispánicas. No obstante, parece acertada su referencia a la importancia del tiempo corto -término utilizado para referirse al paso de la colonia a la república- en el análisis histórico. Creemos que su visión de la independencia como un proceso aún inconcluso, o matizando la idea, que no se ha terminado de desarrollar en plenitud, puede no estar absolutamente acertado. Desde su perspectiva, el quiebre que provocó la Independencia tenía como objeto la transformación de la sociedad, casi de manera revolucionaria.

No sabemos con exactitud si el autor pretende leer en los sucesos de aquellos años una intencionalidad quizás oculta, de subvertir los valores tradicionales y mediante la Independencia tratar de obtener la fundación de una nueva sociedad. En ese caso, creo que esa tesis sería errada, ya que en mi parecer, la Independencia no buscó prácticamente en ninguno de los países independizados, una ruptura tan drástica con el pasado colonial. Por el contrario, nos parece que los grandes pensadores de la Independencia tenían en vista reformas, pero siempre basándose en el modelo existente, teniendo como ejemplos en Chile a don Juan Egaña, Manuel de Salas e incluso posteriormente a Diego Portales.

La postura de Jocelyn-Holt se refleja claramente en la crítica que se realiza al período de los gobiernos conservadores, sosteniendo que ellos fueron un retroceso en el pensamiento republicano nacional ${ }^{42}$, señalándolo expresamente ${ }^{43}$.

En vistas de lo anterior, vemos que la posición que pretende plantear el autor, equivocada o no, nos parece algo parcial a la hora de juzgar los hechos. Culpar a la oligarquía y al autoritarismo establecido a partir de la Constitución de 1833 de haber frenado el ideal republicano que se venía gestando desde la Independencia y que alcanzó su máxima expresión en la Constitución "liberal" de $1828^{44}$, nos parece un anacronismo demasiado evidente. Sin duda la corriente clásica debe ser revisada, especialmente en el estudio del período conocido comúnmente como "la anarquía" (18231829), pero sostener que en aquellos años se verificó uno de los episodios de esplendor republicano, y cargar culpas a la aristocracia local del fracaso de ese episodio, nos parece precipitado. Por lo demás, si bien la necesi-

${ }^{42}$ En este mismo sentido, Carlos Ruiz y Vasco Castillo señalan que "uno podría sostener que el régimen político chileno transita, durante el siglo XIX desde un primer republicanismo, propio del periodo de la Independencia, hacia un republicanismo conservador y luego hacia uno liberal, hacia el fin del siglo" RuIz, Carlos y Castillo, Vasco (2001), p. 1. También Pablo RuizTagle y Renato Cristi señalan que "es necesario reconocer que el curso histórico-constitucional de nuestra República no es de una tradición univoca, que se inicia en 1810 y que continúa inalterada hasta nuestros dias.. en Chile no hemos tenido una, sino cinco Repúblicas, donde cada una corresponde a un periodo particular de nuestra historia". Ruiz-Tagle, Pablo y Cristi, Renato (2006), p. 80.

43 "en un plano estrictamente ideológico, lo que primó en el Chile del XIX fue un liberalismo doctrinario de corte francés, cauto, autoritario, dirigista, desconfiado de la democracia, claramente de la revolución, y al servicio del grupo dirigente oligárquico que, a pesar de los avances modernizantes que estuvo dispuesto a auspiciar o conceder, nunca olvidó que su poder derivaba de una sociedad rural, fuertemente jerarquizada". JocELYNHolt, Alfredo (2005), p. 430.

44 Ruiz-Tagle, Pablo y Cristi, Renato (2006), p. 81. 
dad de plantear una revisión historiográfica sobre el período en cuestión ha sido bien servida por Jocelyn-Holt, es justo aclarar que no se trata de una hipótesis necesariamente novedosa $\mathrm{u}$ original.

De una tendencia similar a la de Jocelyn-Holt -aunque con diferencias marcadas- es Gabriel Salazar, quien pretende realizar un análisis del proceso de Independencia basado en la lucha entre los intereses de clases. En su obra "Construcción de Estado en Chile (1800-1837) Democracia de los pueblos. Militarismo ciudadano. Golpismo oligárquico" (2005), el autor realiza una crítica a los autores clásicos chilenos.

Además de la crítica ya citada a Diego Barros Arana, realiza también una crítica a quienes le siguieron o formaron en su escuela -como Vicuña Mackenna, Amunátegui, Lastarria o Federico Errázuriz- quienes si bien hicieron esfuerzos por crear una línea auténticamente liberal en la historiografía, no supieron separarse de la línea oficial, exaltando las figuras de los generales O'Higgins y Prieto, y la del ministro Portales, dadas la gloria militar del primero, el sablazo del segundo -refiriéndose al triunfo de este en Lircay contra las tropas pipiolasy la genialidad política del último ${ }^{45}$. Pese a ello, el autor realiza gran parte de su trabajo sobre la base de los autores mencionados, ya citándolos o bien partiendo de premisas elaboradas por ellos, defecto que se ve bastante disminuido en relación con errores sobre conceptos jurídicos, tales como "pueblo" o "soberanía". Efectivamente, el autor señala que "las leyes [Siete Partidas] de Alfonso X definían la soberanía del Rey por adcrip-

\footnotetext{
45 Salazar, Gabriel (2006), p. 30. “...La historia de Chile muestra efectivamente que el orden politico hay sido estable y duradero, pero que, con respecto a la soberanía popular, ha sido por más de un siglo un orden ajeno y cosificado... ”. Ídem, p. 17
}

ción a la soberanía comunera”, intentado justificar de este modo el pactismo español, que es más bien propio de siglos posteriores. Efectivamente, la soberanía contenida en las partidas se basa en principios del Ius Commune, derivadas de una concepción absoluta del poder político en manos del gobernante -Emperador-Rey Señor-, y no de una supuesta legitimidad desde la comunidad al monarca. En este sentido, dichos supuestos pactos vinieron a afirmar una posición política que ya se había consolidado a partir del Ius Commune, consolidando la plenitudo potestatis del gobernante ${ }^{46}$. Sin embargo, se entiende la interpretación del autor dentro de su propio contexto historiográfico: se busca resaltar la posición política de la población -incluso en pleno período altomedieval español- para de esta forma afianzar la idea de la relevancia política de los "Pueblos", concepto que nuevamente es malinterpretado por el autor -entendiéndolo como población o democracia-, alejándose de la definición propia de su tiempo: el gobierno de la ciudad, cabeza de población o bien Cabildo ${ }^{47}$.

Como fuere, al parecer sería en base a ese origen personalista que supuestamente sostiene el orden en Chile, que Salazar construiría su crítica la falta de legitimidad de origen del orden político establecido: para él, este debe ser el fruto de la espontánea organización de la ciudadanía (sociedad civil), y no el fruto de personalismos o caudillismos. En este sentido, la exaltación de figuras particulares, ya sean civiles o militares, solo se justifica en la medida en que estas hayan surgido como medios que permitiesen el libre ejercicio de la soberanía

\footnotetext{
46 Clavero, Bartolomé (1994), pp. 36-37.

47 Cfr. García-Huidobro, Cristóbal (2007).
} 
por parte del pueblo ${ }^{48}$. Como el mismo autor señala, los principales estadistas de Chile -ya en crítica no solo dirigida a Portales, sino también a Alessandri y Pinochet-, tienen como "gran mérito público... el haber sido autoritarios, arbitrarios y represivos..." 49 . Por ello Salazar concluye que en Chile la memoria histórica de la nación se encuentra enferma, "saturada de estatuas y héroes que, en estricto rigor histórico y cívico, no han sido ni son ejemplares" 50 , y se ha dejado de lado al pueblo como el principal actor y héroe por naturaleza.

Similar idea plantean los profesores Renato Cristi y Pablo Ruiz-Tagle. En su reciente obra "La República en Chile. Teoría $y$ práctica del constitucionalismo republicano" (2006), reconocen abiertamente su parentesco intelectual con autores del corte de Jocelyn-Holt, en el sentido de replantear el problema del constitucionalismo republicano, democrático y liberal, proyecto que habría quedado en el olvido en 1833 con la Constitución Autoritaria de ese mismo año. Para ellos, no obstante el constitucionalismo chileno ha tenido como inspiración y finalidad las ideas republicanas, democráticas y liberales ${ }^{51}$, su vicio radicaría en su falta de legitimidad de origen, toda vez que este constitucionalismo no se ha fundado en un movimiento ciudadano. Por ello distinguen cinco momentos en el constitucionalismo chileno -cinco repúblicas, al estilo francés-, clasificación que es en mi parecer, original de los autores. Dadas las tendencias constitucionales chilenas, la división por repúblicas se basaría en la percepción del gobierno y los derechos civiles por parte de la nación.

\footnotetext{
48 Salazar, Gabriel (2006), p. 17.

49 Ídem, p. 19

50 Salazar, Gabriel (2006), p. 21.

51 Ruiz-Tagle, Pablo y Cristi, Renato (2006), p. 80
}

Puesto que la clasificación que realizan se remonta hasta nuestros días, solo mencionaremos la primera de ellas, la cual nos interesa por encontrarse en la época de la Independencia y de la formación de la República. Dicha Primera República, como es denominada por los autores, abarcaría el período que va desde 1810, año de la Primera Junta de Gobierno, hasta 1833, año de la constitución autoritaria de Mariano Egaña impulsada por el ministro Diego Portales. Este período, tendría inicios iusnaturalistas, toda vez que se reclaman y alegan como argumentos para la independencia y el autogobierno los derechos esenciales al pueblo y al ciudadano, y a su vez liberal en la concepción de los derechos (como veremos en la Constitución de 1812 y en el proyecto de Juan Egaña de 1813). Luego, desde 1818 a 1823, durante el régimen denominado "Patria Nueva", habría un sello autoritario, marcado por la dureza del régimen de O’Higgins, y que concluiría en 1823 con la abdicación de este y su posterior autoexilio en el Perú. Comienza así la etapa liberal dentro de la primera república, la etapa ciudadana, la etapa de anarquía o de ensayos constitucionales ${ }^{52}$. En este

\footnotetext{
52 Si bien autores importantes han denominado a esta etapa como de "anarquía”, la gran mayoría opina que esta etapa fue "un trozo importante y fecundo de nuestra vida histórica”. HeIse, Julio (1976), p. 21. No obstante el mismo autor reconoce que la desorientación política se tradujo en que "el hombre vaciló frente al surgimiento de nuevas tendencias espirituales". HeIse, Julio (1978), p. 81. Villalobos por su parte, señala que pese a la turbulencia política y sensación de caos, el balance de la época arroja resultados positivos, y por lo mismo "no es posible calificarla de anarquía ni de periodo estéril tenebroso”. VILLALOBos, Sergio (1989), p. 77. Para Edwards en cambio, dicho periodo es sin duda un "interregno anárquico", o bien "periodo de los pipiolos" o del "estado sin forma", durante el cual, "como en los demás países hermanos, los jurisconsultos y los ideólogos perdieron entonces su
} 
período reaparece Infante con sus ensayos federales, una serie de cuerpos legales que no formaron una sola constitución, pero que sí intentaron $-y$ por un breve periodo de tiempo lo lograron- organizar al país de manera federal, siguiendo el ejemplo de los Estados Unidos de América. Este ensayo federal tuvo una efímera existencia, concluyendo con la constitución liberal del año 1828 , la cual también tuvo sus días contados desde la Batalla de Lircay en 1829, en la cual las tropas "pipiolas" comandadas por el general Ramón Freire fueron derrotadas por las tropas al mando del general Prieto. Para estos autores, la Constitución de 1828 interpretó "con gran acierto la realidad histórico-cultural del momento" 53 . Con ella "se logra parcialmente consolidar la primera forma de republicanismo en Chile" 54 , toda vez que ella contempla los mecanismos para lograr una participación y deliberación por parte de los gobernados en relación a los temas públicos. También vino a poner fin a ciertas formas de privilegios sociales y eclesiásticos. Esta Constitución muere con el comienzo de la Segunda República -la República Au-

tiempo redactando constituciones y discutiendo principios de derecho público...". EDWARDS, Alberto (1928, ed. 2005), p. 46. Góngora también se pronuncia en este sentido, al señalarnos que el Estado nacional se consolida luego de este "brevísimo período caótico". GÓNGOrA, Mario (1986), p. 74. Eyzaguirre también habla de anarquía y de crisis de autoridad. EyzAGUIRRE, Jaime (1973), p 117; (1967), p. 69. Collier, sin mencionar la anarquía, sí hace referencia al desorden político que afligió a todos los países ahora independientes, quienes luego de 1820 lucharon contra las autoridades, generalmente militares, que les habían otorgado las independencias, creándose un desorden que se solucionó de dos maneras: o permitir que el caos continuara, o bien someterse a una tiranía personal. Solo Chile, a juicio del autor, supo abstraerse de dicha coyuntura, poniendo coto al desorden pero sin aceptar la tiranía. Collier, Simon (1967), p. 301.

53 Ruiz-Tagle, Pablo y Cristi, Renato (2006), p. 91.

54 Ruiz-Tagle, Pablo y Cristi, Renato (2006), p. 91. toritaria-, que puso fin a ese debate público que supuestamente se había establecido en Chile.

Finalmente, debo mencionar a tres autores difíciles de clasificar en cualquiera de las corrientes antes mencionadas, pero cuya obra no puede quedar fuera del presente estudio: Fernando Campos Harriet, Bernardino Bravo Lira y Sergio Carrasco Delgado.

El primero de ellos aportó a la historiografía constitucional con su trabajo Historia Constitucional de Chile, reeditada en varias ocasiones. Dicho trabajo contempla un inmenso análisis de las fuentes de la época, así como un estudio del contexto histórico en el cual la evolución constitucional se desenvolvió. En efecto, la obra logra conciliar con bastante aplomo tanto la génesis constitucional e institucional, con las causas sociales y políticas que rodeaban dichos procesos, sin menguar en su recurso a las fuentes y discursos que inspiraban el debate constituyente propiamente tal. Destaca como una de las pocas obras de la historiografía constitucional escrita principalmente desde la perspectiva del jurista/ historiador, sin adolecer por ello de un recurso forzado a las distintas corrientes jurídicas que pudieron determinar el proceso político. En consecuencia, no se trata de una mera recopilación de fuentes, o de una interpretación de la historia, o de un libro de historia de filosofía política, sino de una obra completamente dedicada a la historia de las constituciones chilenas, sus modificaciones e interpretaciones.

Bernardino Bravo Lira es un autor difícil de definir en pocas líneas, principalmente por la amplitud de su obra, como por las distintas aristas en que ha enfocado su trabajo. En efecto, Bravo ha trabajado desde temas generales en la Historia del De- 
recho -por ejemplo sobre el período Visigodo en Iberia o el Derecho Común- hasta temas de Derecho Indiano o la formación del Estado chileno, con especial interés sobre temas constitucionales. En este sentido destacan sus obras -quizá más representativas- Por la razón o la fuerza: el Estado de Derecho en la historia de Chile, El Estado Constitucional en Hispanoamérica, o El Absolutismo Ilustrado en Hispanoamérica. Chile 1760-1860 de Carlos III a Portales y Montt. En ellas el autor analiza la evolución de las instituciones políticas en Chile, recurriendo al pasado colonial como fundamento de muchas de ellas. No deja de resultar interesante el análisis de la continuidad jurídica y el parentesco cercano de muchas de las instituciones políticas que se creen propiamente republicanas con el régimen indiano, el cual resulta muchas veces demostrado por el autor.

Finalmente, Sergio Carrasco ha aportado a la historiografía constitucional local con un trabajo titulado Génesis y Vigencia de los textos constitucionales chilenos, recientemente actualizado. El trabajo resulta de gran utilidad para una buena comprensión del proceso constituyente -los intervinientes y los mecanismos de elaboración-, así como la vigencia efectiva de cada uno de los textos constitucionales. Sin embargo, se echa de menos un análisis que sirva para una mejor comprensión del contexto en el cual los textos fueron promulgados, o bien un estudio comparativo de los mismo que ayude a establecer una posible filiación entre los mismos.

Podemos concluir entonces que la historiografía constitucional chilena no ha tenido un desarrollo uniforme ni continuo por parte de la historiografía chilena. Muy por el contrario, la historia constitucional se ha debido nutrir de otras disciplinas, como la historia política, la historia institucional o la historia social. Recientemente, el profesor Eric Palma ha publicado su obra "Estado Constitucional Liberal Católico en Chile (1812-1924), texto que presenta la historia constitucional chilena desde la perspectiva del liberalismo y los principios que lo informan, a saber, la soberanía popular nacional, representativa y democrática. Esta tesis se contrapone precisamente a la continuidad que plantean otros profesores como Antonio Dougnac, quien ve, hasta cierto punto y con bastante acierto, una continuidad de los principios indianos en las cartas constitucionales chilenas del $S$. XIX. Del mismo modo, la tesis del profesor Bravo Lira no se aleja radicalmente de lo supuesto por el profesor Dougnac, como sostiene Palma en su libro, toda vez que la invalidez de los textos constitucionales no es absolutamente incompatible con la proyección indiana.

Los historiadores constitucionales chilenos propiamente tales -Briceño, Galdames, Eyzaguirre, Campos Harriet (este último con matices) y Carrasco Delgadohan tomado los textos constitucionales chilenos y los han presentado desde una perspectiva esencialmente cronológica, separando el proceso en etapas bien delimitadas, y encuadrando los textos en estudio dentro de ellas. Esto se presenta inadecuado para una compresión cabal de los textos, toda vez que los mismos deben ser estudiados desde dos perspectivas: en primer lugar, en su contexto histórico, económico y social. Ello implica realizar un análisis detallado del imaginario cultural en el cual se desenvolvían los principales redactores constitucionales, hombres de opinión y grupos de interés político, incluso aquellos que no ostentaban un poder fáctico importante, sino más bien un poder blando. En 
segundo lugar, los textos deben estudiarse en su propio contenido, es decir, contrastar los principios que informan cada uno de los mismos, y de esta forma elaborar una genealogía constitucional chilena.

En mi parecer, se presenta como necesario contar con una propuesta historiográfica que pretenda conciliar algunas las corrientes ya mencionadas.

Por una parte, debemos considerar el liberalismo gaditano propiamente tal. Este movimiento liberal "a la española", tiene la particularidad de presentar las ideas ilustradas de manera restringida, debido al fin último que se perseguía en las Cortes de Cádiz: limitar el poder absoluto del monarca. El contexto en el cual la carta de Cádiz fue dictada, al igual que en el caso de los primeros textos o ensayos constitucionales americanos, fue un período de guerra y confusión política, y por lo mismo, no debe extrañar a nadie que una vez restablecido Fernando en el trono, echara por tierra todo lo obrado, con una gran adhesión a su causa. Pese a las amplias facultades que el monarca conservaba bajo la Constitución de 1812, el campo aún no estaba fértil como para sembrar un liberalismo moderado de manera constitucional. En Chile, este modelo tuvo cuatro manifestaciones: el Reglamento Provisorio de 1812, la Constitución Provisoria de 1818, la Constitución Permanente de 1822 y la Constitución Liberal de 1828. En todas ellas se intentó plasmar un liberalismo moderado de corte gaditano, sin éxito permanente en ninguno de los casos.

Una segunda hipótesis se ve en los ensayos federales del lustro liberal, entre 1823 y 1828. El proyecto federal se nos presenta como otra variable del liberalismo, en su vertiente localista. El liberalismo político efectivamente tuvo una manifestación distinta en este caso, toda vez que no se comprendía de la manera clásica: Estado de Derecho, igualdad ante la Ley y soberanía nacional. Muy por el contrario, la idea de que subyacía en el federalismo chileno era la mera idea de la representación local como forma de representación política, estableciendo diferencias territoriales y una participación política de corto alcance. Estas ideas no podrían haber llegado a buen puerto por los mismos motivos que la historiografía liberal decimonónica atribuyó como causal de fracaso a la Carta Moralista de 1823 , esto es, la falta de preparación adecuada de la ciudadanía y la creación de organismos, magistraturas e instituciones ajenas al imaginario político chileno.

Una tercera corriente constitucional la vemos en los proyectos egañianos. Si bien para esta afirmación solamente contempló el Proyecto Constitucional de 1811 y la Carta de 1823 -excluyendo el breve Proyecto de 1827-, ellos bastan para establecer una genealogía propia, basada en la síntesis de las ideas indianas con el catolicismo ilustrado propio de Juan Egaña. Y la afirmación se basa en el simple estudio de los textos mencionados, en los cuales se ve el forzado intento por conciliar el pasado hispánico propiamente indiano con las nuevas ideas que debían iluminar a una república liberal. No es de extrañar entonces que las ideas recogidas en estos textos fuesen muy difíciles de aplicar, pese a la costumbre que sobre ellas ya existía. Los tiempos requerían de un cambio en la el sistema político, el régimen administrativo y la legislación interna, y el modelo egañiano era demasiado conciliador con el Antiguo Régimen, pese a ciertas novedades introducidas, como por ejemplo el establecimiento de registros de nacimientos, matrimonios y defunciones (Código Moral). Finalmente, tenemos la Carta de 1833. Esta obra puede definirse como una 
descendiente de dos corrientes constitucionales distintas, de acuerdo a la clasificación genealógica que hemos presentado: por una parte recibe gran influencia del liberalismo gaditano, en cuanto influencia de los principios constitucionales que recoge de aquel texto, mientras que a su vez, y esto debido a que el fruto usualmente no cae muy lejos de su árbol, recibe cierta influencia de la corriente egañiana recién mencionada. Todo lo anterior queda de manifiesto en el fuerte presidencialismo que se viene a consagrar -autoritarismo presidencialista o dictadura legal como algunos lo han llamado- el cual también obedece al modelo indiano, plasmado bajo la influencia de Portales. Lo que Edwards ha denominado acertadamente, una idea "nueva de puro vieja".

Por todo lo anterior creo conveniente comenzar una historiografía constitucional que agrupe a nuestras cartas fundamentales y las estudie no solamente en su contexto cultural, sino que también "familiar". La relevancia de este acercamiento, fuera de su impacto pedagógico, radica en que se verá al proceso de génesis constitucional no de manera aislada en hitos distintos, sino que como un proceso completo e interconectado, debiendo entender nuestro bagaje constitucional desde una perspectiva histórica. La importancia de esto último radica en que debemos comprender que la Constitución, como obra jurídica, es más que la sumatoria de un número de artículos que regulan nuestra vida política y establecen nuestros límites jurídicos, económicos y sociales, sino que es el producto de un largo transcurso de tiempo en el cual dichos parámetros se han ajustado a una determinada forma de ser. En consecuencia, nuestra Constitución debe ser el reflejo de nuestro "constitucionalismo histórico" -en términos burkeanos y egañianos-, respetando los principios asimilados en el imaginario político chileno, alejándonos de ensayos caribeños ajenos a nuestro contexto político, jurídico y social.

\section{FUENTES}

El Araucano, periódico (1830-1877).

Epistolario de Diego Portales (Santiago de Chile, Universidad Diego Portales, 2004), 2 Tomos.

Recabarren, Luis Emilio (1910): Ricos y pobres, discurso.

\section{BIBLIOGRAFÍA}

Amunátegui, Miguel Luis (1879): Los Precursores de la Independencia de Chile (Santiago de Chile, Imprenta de la República de Jacinto Núñez).

Campos, Fernando (1951): Historia Constitucional de Chile (Santiago, Editorial Jurídica de Chile).

Carrasco, Sergio (1983): Génesis y vigencia de los textos constitucionales chilenos (Santiago de Chile, Editorial Jurídica).

Clavero, Bartolomé (1994): Historia del Derecho: Derecho Común (España, Ediciones de la Universidad de Salamanca).

Collier, Simon (2012): Ideas y política de la independencia chilena. 1810-1833 (Santiago, Fondo de Cultura Económica).

Donoso, Ricardo (1969-1970): Francisco A. Encina simulador (Santiago de Chile, Editorial Ricardo Neupert).

Encina, Francisco (1935): La literatura histórica chilena y el concepto actual de la Historia (Santiago de Chile, Editorial Universitaria, Edición 1997).

Eyzaguirre, Jaime (2004): Fisionomía histórica de Chile (Santiago de Chile, Editorial Universitaria, decimoséptima edición). 
(1973): La Logia Lautarina y otros estudios sobre la independencia (Buenos Aires, Editorial Francisco de Aguirre).

(1957): Historia de las Instituciones politicas $y$ sociales de Chile (Santiago de Chile, Editorial Andrés Bello).

Feliú, Guillermo (1934): Barros Arana y el método analitico en la historia (Santiago de Chile, Editorial Nascimento).

Galdames, Luis (1925): Historia de Chile. La evolución constitucional 1810-1925 (Santiago de Chile, Imprenta Balcells \& Co.).

García-Huidobro, Cristóbal (2007): “Gabriel Salazar Vergara: Construcción de Estado en Chile (1800-1837). Democracia de los "pueblos", militarismo ciudadano, golpismo oligárquico”, en Historia, 40.

Gazmuri, Cristián (2006): La historiografia chilena (1842-1970) (Santiago de Chile, Editorial Taurus), 2 Tomos.

Góngora, Álvaro (1990): "El estado en Mario Góngora, una noción de contenido spengleriano", en Historia, 25.

Góngora, Mario (1986): Ensayo histórico sobre la noción de Estado en Chile en los siglos XIX y XX (Santiago de Chile, Editorial Universitaria).

González, Javier (1968): “Hernán Ramírez Necochea: Antecedentes económicos de la independencia de Chile", en Historia, 7, pp. 373-375.

Heise, Julio (1976): 150 años de evolución institucional (Santiago de Chile, Editorial Andrés Bello).

Jocelyn-Holt, Alfredo (1985): "El desarrollo de una conciencia pública en Lastarria y Sarmiento", Estudios Públicos, 17.
Krebs, Ricardo (1985): "El historiador Mario Góngora", en Historia, 20.

Quintero, Gilberto (2007): "La historiografía de las independencias americanas: nuevos enfoques y temas (1980-2000)", en Anuario de Estudios Bolivarianos, 14, pp. 97-126.

Ramírez, Hernán (1959): Antecedentes económicos de la Independencia de Chile (Santiago de Chile, Universidad de Chile).

Ruiz, Carlos y Castillo, Vasco (2001): “El pensamiento republicano en Chile durante el siglo XIX: notas de investigación", en Revista Jurídica de la Universidad de Puerto Rico, 70 (4).

Ruiz-Tagle, Pablo y Cristi, Renato (2006): La República en Chile. Teoría y práctica del constitucionalismo republicano (Santiago de Chile, LOM Ediciones).

Salazar, Gabriel (2005): Construcción de Estado en Chile (Santiago de Chile, Editorial Sudamericana).

Villalobos, Sergio (1967): Tradición y Reforma en 1810 (Santiago de Chile, RIL Ediciones, segunda edición 2006).

(1989): Portales, una falsificación histórica (Santiago de Chile, Editorial Universitaria).

Vial, Gonzalo (1965): "Historiografía de la independencia de Chile", en Revista de Historia de América, 59. Vitale, Luis (1967): Interpretación marxista de la Historia de Chile (Santiago de Chile, Prensa Latinoamericana). 